\title{
ELECTROCARDIOGRAPHIC COMPARISONS IN TOTAL INTRAVENOUS ANESTHESIA (TIVA) USING PROPOFOL, THIOPENTAL SODIUM AND PROPOFOL - THIOPENTAL SODIUM COMBINATION IN CANINE
}

\author{
F. MRIDHA ${ }^{* 1}$, S. HALDER ${ }^{2}$ AND C. K. GHOSH ${ }^{1}$ \\ ${ }^{1}$ Department of Veterinary Clinical Complex, West Bengal University of Animal and Fishery Sciences, \\ 37, K. B. Sarani, Kolkata - 700 037, West Bengal, India \\ ${ }^{2}$ Department of Veterinary Surgery and Radiology, West Bengal University of Animal and Fishery \\ Sciences, 37, K. B. Sarani, Kolkata - 700 037, West Bengal, India
}

\begin{abstract}
In present study total 18 clinical cases of dogs in three groups containing 6 cases in each group were anesthetized by propofol (Group I), thiopental sodium (Group II) and their mixture (Group III). The electrocardiographic study was done before anaesthesia, during anaesthesia (15 minutes after anaesthesia) and after complete recovery by using CT 200 VET Electrocardiograph. The subjects before the anaesthesia were considered as control and compared with the data obtained during anaesthesia and after recovery. Different values of waves and complexes of ECG were compared with the reference values mentioned by Tilley (1992). ECG observations showed no detectable changes regarding $P$ wave amplitude and duration in four animals of group I, however, shorter QT interval and no ventricular arrhythmia were noted in five animals of group I. In group II, P wave with normal configuration were noted in five animals, idioventricular tachycardia were noted in two cases, increased QT intervals were also noted in four animals and QRS complex were wide but within normal physiological range in four animals. In group III, no detectable changes between pre-anaesthetic and during anaesthesia in regards to amplitude and duration of $P$ wave were noted in 5 cases although QRS complex also changed appreciably but within physiological range. Larger $T$ wave were noted in four animals. In the present electrocardiographic study for total intravenous anaesthesia in dog, propofol-thiopental sodium mixture was found most effective due to less cardiovascular effect.
\end{abstract}

Key words: Electrocardiographic study, Propofol, Thiopental sodium

Propofol, 2, 6-diisopropylphenol, a potent hypnotic/sedative is believed to be an ideal agent for TIVA (Campbell et al., 2001). But it is expensive with side effects like apnoea, myoclonus, myocardial depression without much hypotension, bacterial contamination and failure to block autonomous response to noxious stimuli. Thiopental sodium, an ultra-sound acting barbiturate is less likely to induce apnoea, does not trigger malignant hyperthermia, induces tachycardia and inexpensive. Disadvantages of thiopental sodium include slow clearance, leading to prolonged, rough recovery and severe hypotension. In the present investigation, electrocardiographic study has been conducted to evaluate the cardiovascular effect in $\operatorname{dogs}$ anesthetized by propofol, thiopental sodium and their mixture (1:1) separately.

\footnotetext{
*Corresponding Author
} 


\section{MATERIALS AND METHODS}

The study was conducted on a total 18 clinical cases in three groups containing 6 cases in each group of different breeds of dogs aged between 2 to 6 years. The anesthesia was induced by IV bolus which was one quarter of the total dose of propofol (@8 mg/kg body weight) in Group I, thiopental sodium (@ $20 \mathrm{mg} / \mathrm{kg}$ body weight) in Group II and propofol-thiopental sodium mixture (1 $\mathrm{mL}$ of mixture contains $5 \mathrm{mg}$ propofol and $12.5 \mathrm{mg}$ thiopental sodium) @ $1 \mathrm{~mL} / \mathrm{kg}$ body weight in Group III. Immediately after induction anaesthesia was maintained by repeated intermittent bolus injection of one quarter of the left dose. Electrocardiographic study was done before anaesthesia, during anaesthesia (15 minutes after medication of anaesthesia) and after recovery using CT 200 VET Electrocardiograph (Macquarie Medical Systems Pty Limited, 301 Catherine St., Leichhardt, NSW 2040). The animals were kept in right lateral recumbency and electrocardiograms were recorded in all the bipolar and augmented unipolar leads viz. I, II, III, aVR, aVL and aVF at a paper speed of 25 $\mathrm{mm} / \mathrm{sec}$ and at voltage calibration of $10 \mathrm{~mm} /$ $\mathrm{mV}$. The subjects before the anaesthesia were taken as control and compared with the data obtained during anaesthesia and after recovery. Different values of waves and complexes of ECG were compared with the reference values mentioned by Tilley (1992).

\section{RESULTS}

Propofol: No detectable changes regarding $\mathrm{P}$ wave amplitude and duration were noted in 4 animals. However, shorter QT intervals were observed in five animals. No ventricular arrhythmia was noted in five animals of Group I. Intermittent increased P-P' interval was noted indicating sinus arrhythmia.

Thiopental sodium: In Group II, $\mathrm{P}$ wave with normal configuration were noted in five animals, idioventricular tachycardia were noted in two cases, increased QT intervals were also noted in four animals and QRS complex were wide but within normal physiological range in four animals. Larger $\mathrm{T}$ wave were observed in all animals.

Propofol-thiopental sodium (1:1) mixture: In Group III, no detectable changes between preanaesthetic and during anaesthesia in regards to amplitude and duration of $\mathrm{P}$ wave were noted in 5 cases. Although QRS complex changed appreciably, but within physiological range. Larger $\mathrm{T}$ wave were noted in four animals.

\section{DISCUSSION}

Propofol: QT interval varies inversely with the heart rate (Tilley, 1992). As the heart rate following propofol induction were decreased (Cattai et al., 2015), thus shortening of QT interval is justified in the present study. HenaoGuerrero and Ricco (2014) and Silva et al. (2011) found increase in heart rate following induction with propofol. Increased QT intervals in propofol anaesthesia were also reported by Selmi et al. (2002) which is not in agreement to our study. However, Davidowski and Wolf (1984) opined that heart rate and QT interval are governed separately by different sympathetic neurons that may or may not be activated together. Increased QT interval in propofol anaesthesia also found by Selmi et al. (2002). Absence of ventricular arrhythmia in our study corroborated with the findings of Vernooy et al. (2006).

Thiopental sodium: The QT interval was markedly affected by heart rate (Kittleson and Kienle, 1998). Prolonged QT interval in thiopentone anaesthesia was also found by Kleinsasser et al. (2000) whereas Bhat et al. (2017) observed no major differences in QT interval. Ventricular arrhythmia was also noted, which was transient and corroborated with the findings of Muir (1977a and 1977b). These changes were probably related to increased arterial pressure and imbalance between parasympathetic and sympathetic tone (Tilley, 1992). Larger T wave was observed in all animals which might be due to the myocardial hypoxia. 


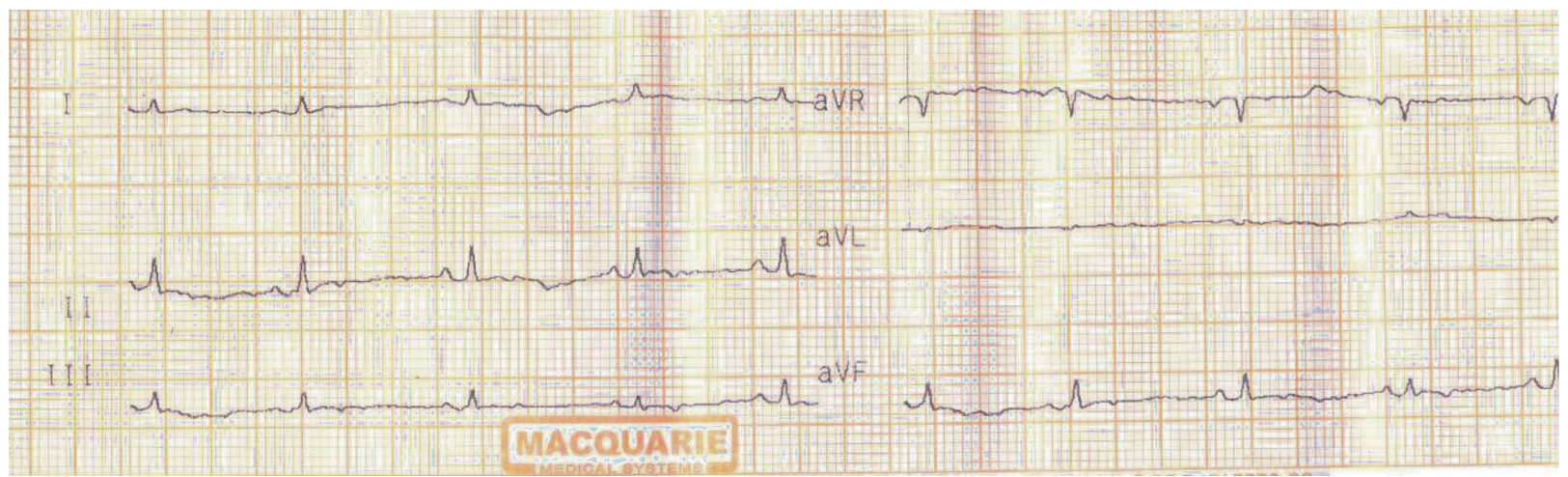

Fig. 1. Electrocardiograph in a Group I dog before induction under the present study at a paper speed of $25 \mathrm{~mm} / \mathrm{sec}$ and the voltage calibration of $10 \mathrm{~mm} / \mathrm{mV}$

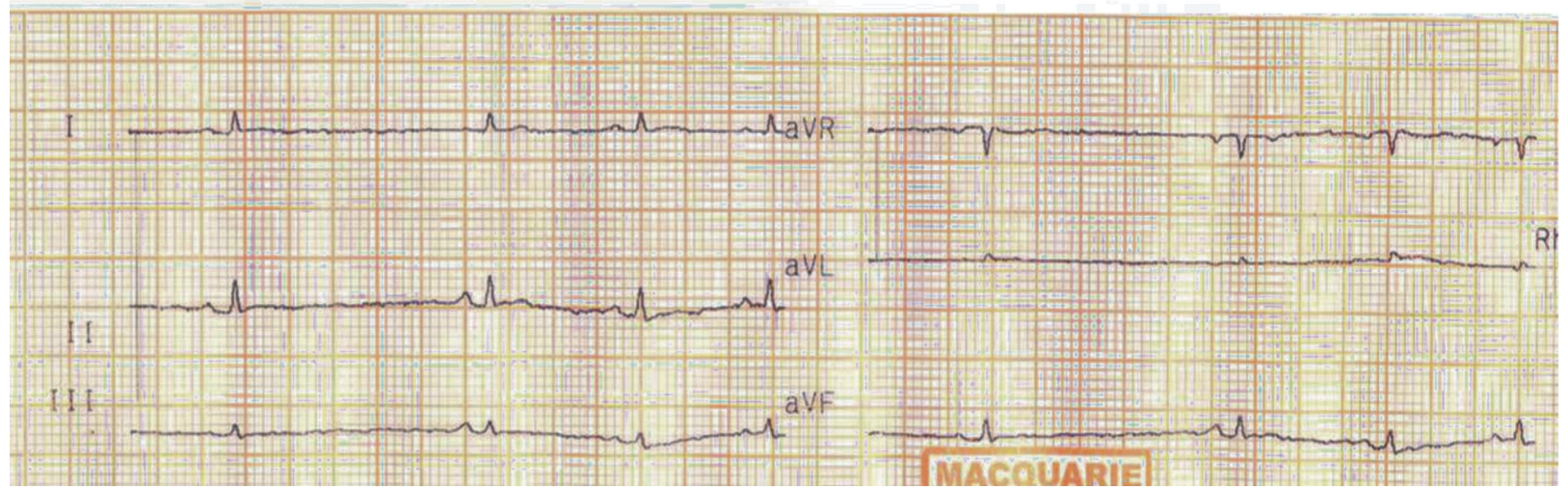

Fig. 2. Electrocardiograph in a Group I dog during maintenance of anaesthesia under the present study at a paper speed of $25 \mathrm{~mm} / \mathrm{sec}$ and the voltage calibration of $10 \mathrm{~mm} / \mathrm{mV}$

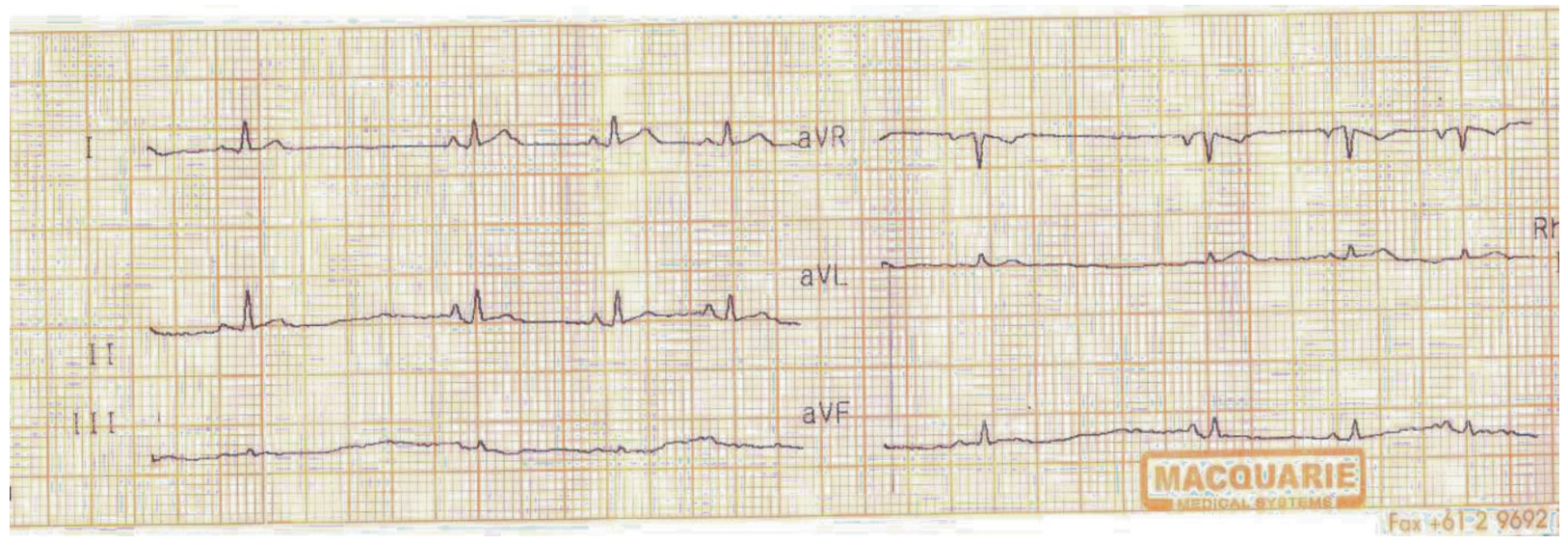

Fig. 3. Electrocardiograph in a Group I dog after recovery under the present study at a paper speed of $25 \mathrm{~mm} / \mathrm{sec}$ and the voltage calibration of $10 \mathrm{~mm} / \mathrm{mV}$ 

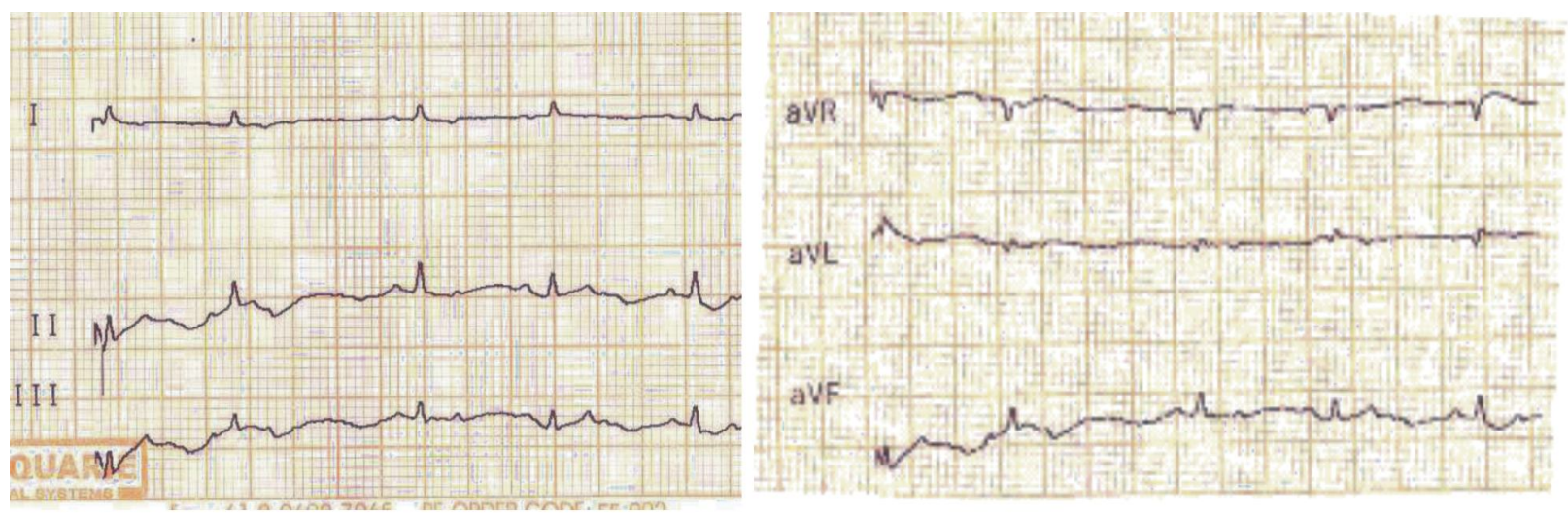

Fig. 4. Electrocardiograph in a Group II dog before induction under the present study at a paper speed of $25 \mathrm{~mm} / \mathrm{sec}$ and the voltage calibration of $10 \mathrm{~mm} / \mathrm{mV}$

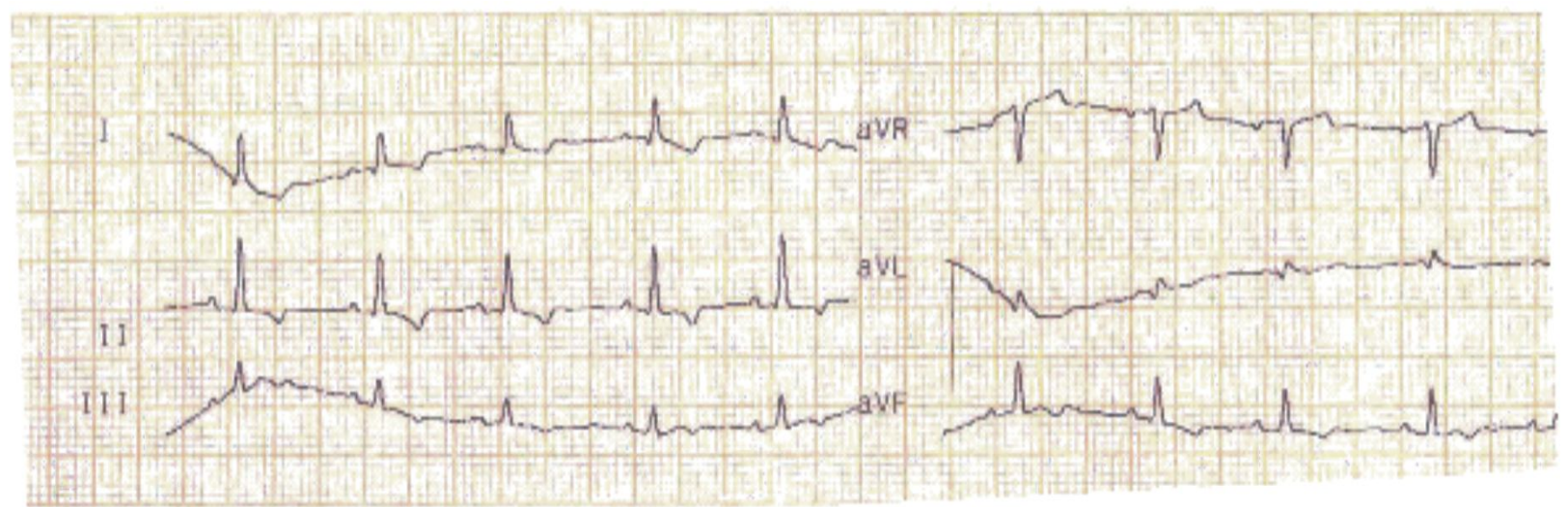

Fig. 5. Electrocardiograph in a Group II dog during maintenance of anaesthesia under the present study at a paper speed of $25 \mathrm{~mm} / \mathrm{sec}$ and the voltage calibration of $10 \mathrm{~mm} / \mathrm{mV}$

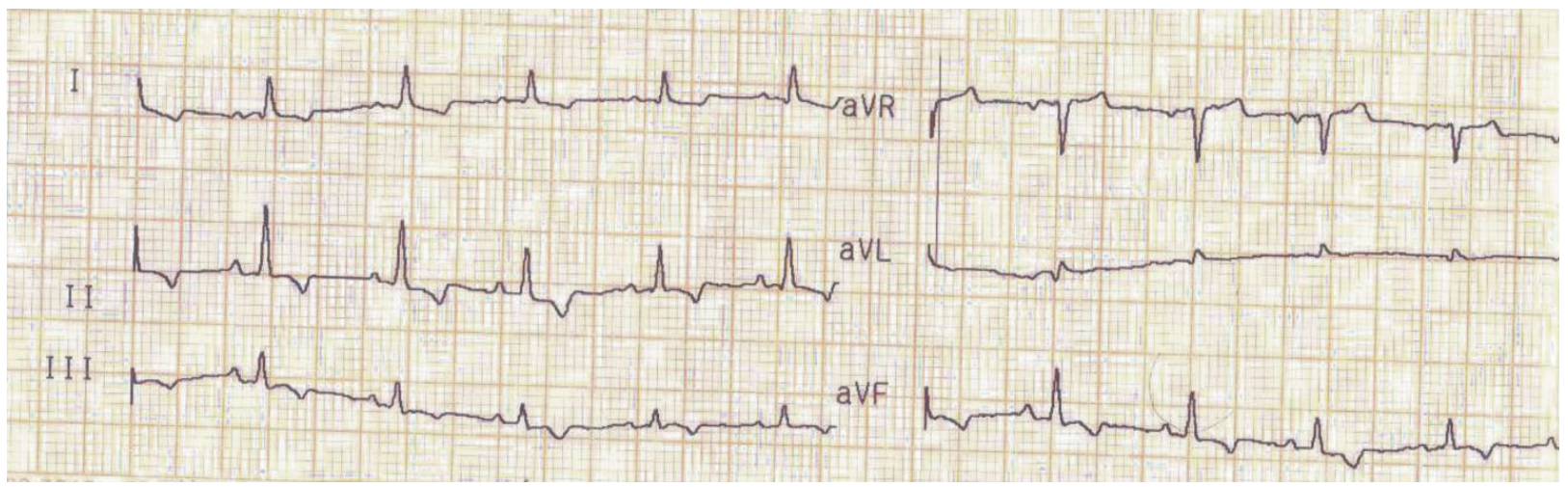

Fig. 6. Electrocardiograph in a Group II dog after recovery under the present study at a paper speed of $25 \mathrm{~mm} / \mathrm{sec}$ and the voltage calibration of $10 \mathrm{~mm} / \mathrm{mV}$ 


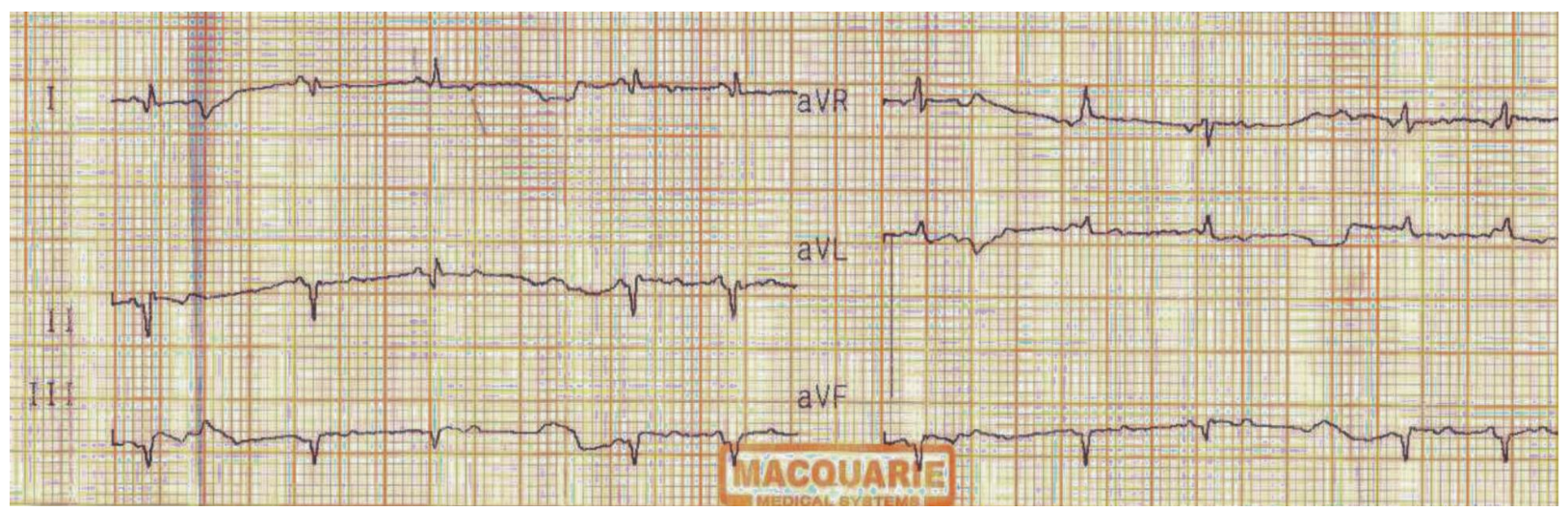

Fig. 7. Electrocardiograph in a Group III dog before induction under the present study at a paper speed of $25 \mathrm{~mm} / \mathrm{sec}$ and the voltage calibration of $10 \mathrm{~mm} / \mathrm{mV}$

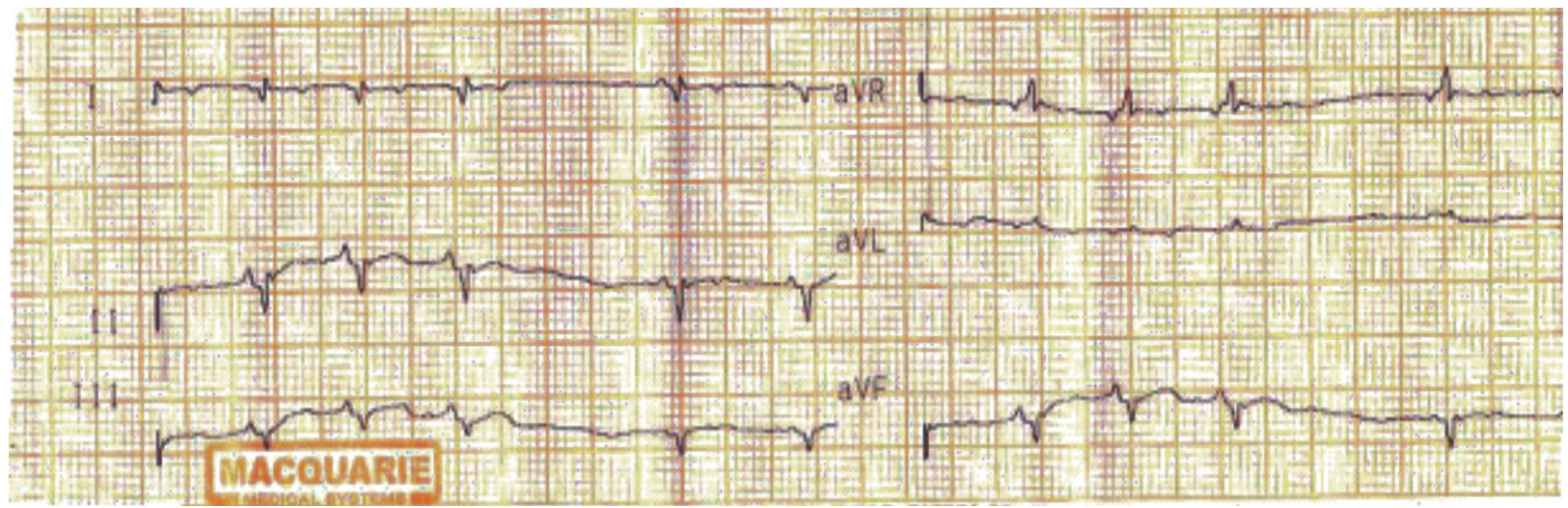

Fig. 8. Electrocardiograph in a Group III dog during maintenance of anaesthesia under the present study at a paper speed of $25 \mathrm{~mm} / \mathrm{sec}$ and the voltage calibration of $10 \mathrm{~mm} / \mathrm{mV}$

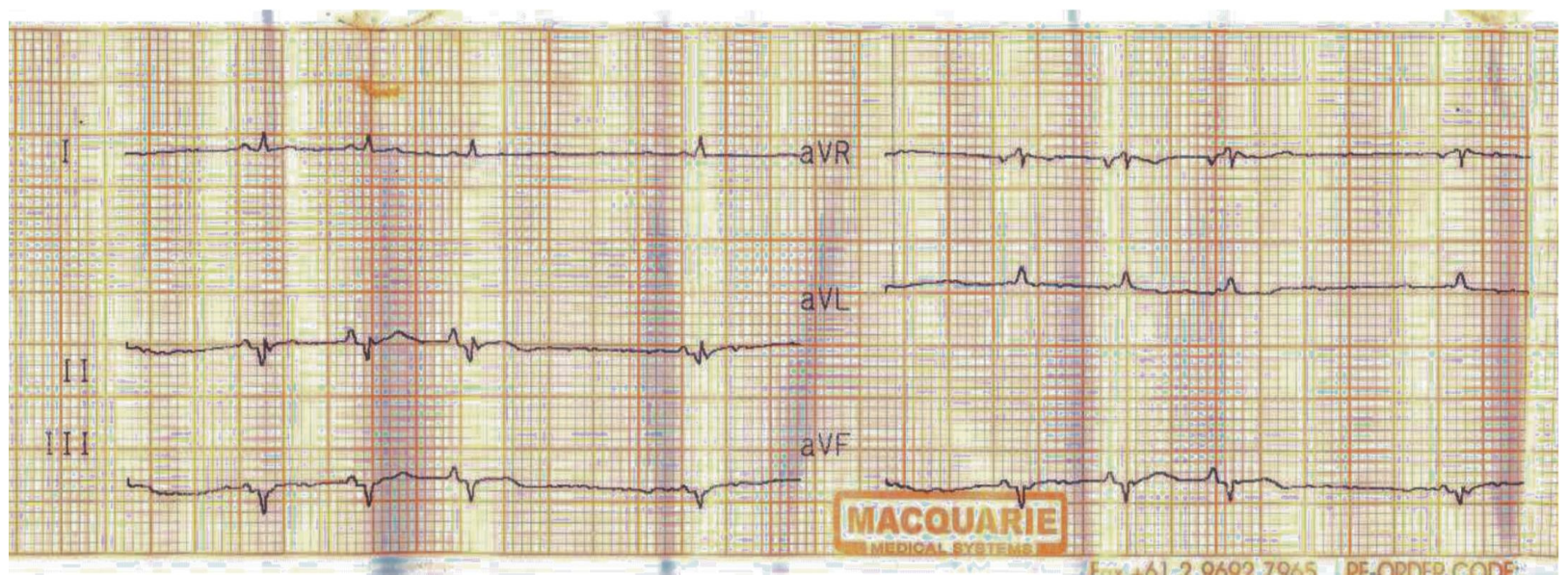

Fig. 9. Electrocardiograph in a Group III dog after recovery under the present study at a paper speed of $25 \mathrm{~mm} / \mathrm{sec}$ and the voltage calibration of $10 \mathrm{~mm} / \mathrm{mV}$ 
Propofol-thiopental sodium (1:1) mixture: Larger $\mathrm{T}$ wave in four animals was probably due to the myocardial hypoxia. The T-wave direction, amplitude and duration depend on many variables, making changes difficult to interpret. Any changes that are noted are generally nonspecific (Kittleson and Kienle, 1998).

\section{REFERENCES}

Bhat AR, Sultan F, Bhatt J, Amarpal, Mohan Det al., 2017. Effect of thiopentone and thiopentone-vecuronium total intravenous anesthesia on haematological, biochemical and electrocardiographic parameters in dogs. Toxicol Int, 24(3): 261-268

Campbell L, Enbergs FH and Kenny GNC, 2001. Total intravenous anaesthesia. CPD Anaest, 3(3): 109119

Cattai A, Rabozzi R, Natale V and Franki P, 2015. The incidence of spontaneous movements (myoclonus) in dogs undergoing total intravenous anaesthesia with propofol. Vet Anaesth Analg, 42: $93-98$

Davidowski TA and Wolf S, 1984. The QT interval during reflex cardiovascular adaptation. Circulation, 69(1): 22-25

Henao-Guerrero $\mathrm{N}$ and Ricco CH, 2014. Comparison of the cardiorespiratory effects of a combination of ketamine and propofol, propofol alone or a combination of ketemine and diazepam before and after induction of anesthesia in dogs sedated with acepromazine and oxymorphone. Am J Vet Re, 75: 231-239

Kittleson MD and Kienle RD, 1998. Small Animal Cardiovascular Medicine. Mosty St Louis, pp72-94

Kleinsasser A, Kuenszberg E, Loeckinger A, Keller C,
Amongst the anesthetic combinations used in the present study for total intravenous anaesthesia in dog, propofol-thiopental sodium mixture was found most effective than either propofol alone or thiopental sodium alone, due to less cardiovascular effect.

Hoerrmann C et al., 2000. Sevoflurane, but not propofol, significantly prolongs the Q-T interval. Anesth Analg, 90: 25

Muir WW, 1977a. Thiobarbiturate-induced dysrythmias: The role of heart rate and autonomic imbalance. Am J Vet Res, 38: 1377

Muir WW, 1977b. Electrocardiographic interpretation of thiobarbiturate-induced dysrythmias in dogs. J Am Vet Med Assoc, 170: 1419

Selmi AL, Santos PSP, Rezende ML, Nunes N, Mc Manus C et al., 2002. Electrocardiographic changes in dogs under propofol sevoflurane anaesthesia after premedication with levomepromazine. Arquivo Brasilerio-de medicina Veterinaria-e-Zootecnia, 54(6): 581-585

Silva A, Ribeiro LM, Bressan N, Oliviera P, Ferreira DA et al., 2011. Dogs mean arterial pressure and heart rate responses during high propofol plasma concentrations estimated by a pharmacokinetic model. Res Vet Sci, 91: 278-280

Tilley LP, 1992. Essentials of Canine and Feline Electrocardiography. $3^{\text {rd }}$ edn., Philadelphia: Lea \& Febiger, pp127-207

Vernooy K, Delhass T, Cremor OL, Diego JMD, Oliva A et al., 2006. Electrocardiographic changes predicting sudden death in propofol related infusion syndrome. Heart Rhythm, 3(2): 131-137

Received - 12.03.2020, Accepted - 17.05.2020, Published - 01.06.2020 